\title{
Gender impact on the correlation between thyroid function and serum lipids in patients with differentiated thyroid cancer
}

\author{
XUE LI $^{1}$, ZHAOWEI MENG ${ }^{1}$, JIAN TAN ${ }^{1}$, MING LIU ${ }^{2,3}$, QIANG JIA ${ }^{1}$, GUIZHI ZHANG ${ }^{1}$, YAJING HE ${ }^{1}$, \\ QING ZHANG ${ }^{4}$, LI LIU ${ }^{4}, \mathrm{KUN} \mathrm{SONG}^{4}$, QING HE${ }^{2}$, MEI ZHU $^{2}$, SHEN WANG ${ }^{1}$, JIANPING ZHANG ${ }^{1}$, \\ WEI ZHENG ${ }^{1}$, RENFEI WANG ${ }^{1}$, TIANPENG HU ${ }^{1}$, NA LIU $^{1}$ and ARUN UPADHYAYA ${ }^{1}$
}

\begin{abstract}
Departments of ${ }^{1}$ Nuclear Medicine and ${ }^{2}$ Endocrinology and Metabolism, Tianjin Medical University General Hospital, Tianjin 300052, P.R. China; ${ }^{3}$ Division of Metabolism, Endocrinology and Diabetes, University of Michigan Medical Center, Ann Arbor, MI 48109, USA; ${ }^{4}$ Department of Health Management, Tianjin Medical University General Hospital,
\end{abstract} Tianjin 300052, P.R. China

Received May 1,2015; Accepted September 1, 2016

DOI: $10.3892 / \mathrm{etm} .2016 .3701$

\begin{abstract}
The present study aimed to explore the association between thyroid stimulating hormone (TSH) and serum lipids in patients with differentiated thyroid cancer (DTC), with a focus on the risk of hyperlipidemia between different genders. The study included 352 DTC patients who were ready to receive I-131 therapy as well as 352 matched normal controls. In the DTC group, 157 patients were monitored for TSH and lipid parameters prior to and after 1 month of thyroxine therapy. Results were analyzed using t-tests, Pearson bivariate correlation and binary logistic regression analyses. All participants were divided into 3 subgroups according to TSH levels: Subgroup 1 (normal TSH level), subgroup 2 (TSH between 5 and $30 \mu \mathrm{IU} / \mathrm{ml}$ ), and subgroup 3 (TSH $>30 \mu \mathrm{IU} / \mathrm{ml}$ ). Serum total cholesterol (TC), triglycerides (TG), and low-density lipoprotein-cholesterol (LDL-C) levels were significantly higher in the DTC group than in the control group. The levels of these parameters decreased after thyroxine therapy and significant positive correlations were observed between TSH and TC, and TG and LDL-C in both genders. Binary logistic regression demonstrated that female
\end{abstract}

Correspondence to: Dr Zhaowei Meng or Dr Jian Tan, Department of Nuclear Medicine, Tianjin Medical University General Hospital, 154 Anshan Road, Tianjin 300052, P.R. China

E-mail: jamesmencius@163.com

E-mail: tanpost@163.com

Abbreviations: TSH, thyroid-stimulating hormone; DTC, differentiated thyroid cancer; TC, total cholesterol; TG, triglycerides; HDL-C, high-density lipoprotein cholesterol; LDL-C, low-density lipoprotein cholesterol; $\mathrm{FT}_{3}$, free triiodothyronine; $\mathrm{FT}_{4}$, free thyroxine; UA, uric acid; FG, fasting glucose; BMI, body mass index; OR, odds ratio; LPL, lipoprotein lipase; HL, hepatic lipase; SR-BI, scavenger receptor $\mathrm{BI}$

Key words: differentiated thyroid cancer, thyroid stimulating hormone, gender, total cholesterol, low-density lipoprotein-cholesterol
DTC patients had higher risks of developing hyperlipidemia than male patients, and these risks increased when TSH increased. For example, the odds ratios (ORs) of high TC in subgroup 2 were 3.30 in males and 4.60 in females, respectively. However, in subgroup 3, the ORs were 9.40 in males and 13.12 in females, respectively. The results of the present study showed that after thyroidectomy, the risk of dyslipidemia markedly increased in DTC patients. More importantly, female patients had a higher risk than male patients.

\section{Introduction}

Following total thyroidectomy, patients with differentiated thyroid cancer (DTC) who are to receive radioiodine-131 (I-131) therapy should be in a state of overt hypothyroidism in order to achieve optimal therapeutic outcomes (1). Such patients have low levels of thyroid hormones and an increased level of thyroid-stimulating hormone (TSH). Under these circumstances, the concentrations of serum lipids are always elevated. Thyroid hormone is known to have significant effects on lipid metabolism (2-4). Although numerous studies have been conducted to assess the association between thyroid dysfunction and hyperlipidemia (4-9), to the best of our knowledge, this association in DTC patients has never been investigated before. In addition, previous studies have revealed that age and gender could influence this association; however, the observations were not consistent (9-12). The present study aimed to investigate the correlation between thyroid function and lipid metabolic profile in patients with DTC, with an focus on differences resulting from different genders.

\section{Materials and methods}

Study population. The subjects studied were selected from the hospitalized DTC patient data archive in the Department of Nuclear Medicine of Tianjin Medical University General Hospital between January 2010 and January 2014. The entry criteria were as follows: DTC patients who had previously undergone total or near-total thyroidectomy and were ready 
for I-131 therapy. The exclusion criteria were as follows: Patients with coronary heart, chronic liver and chronic renal diseases, uncontrolled diabetes mellitus and those who had taken lipid-lowering drugs or other treatments that potentially influenced the lipid profile. Information on the medication and a history of previous diseases for each patient was obtained in detail. In total, 352 DTC patients (89 males and 263 females) were included with adequate information for the analysis. The gender- and age-matched healthy control participants $(n=352)$ were selected from the data archive in the Department of Health Management in the General Hospital of Tianjin Medical University. The control participants, who came to receive an annual health checkup, had a normal thyroid profile and no history of any known diseases.

Blood samples were obtained following overnight fasting for the measurements of serum free triiodothyronine $\left(\mathrm{FT}_{3}\right)$, free thyroxine $\left(\mathrm{FT}_{4}\right)$ and $\mathrm{TSH}$ using a fully automated ADVIA Centaur analyzer (Siemens Healthcare Diagnostics, Erlangen, Germany) by chemiluminescence. Total cholesterol (TC), triglycerides (TG), low-density lipoprotein cholesterol (LDL-C), high-density lipoprotein cholesterol (HDL-C), uric acid (UA) and fasting glucose (FG) levels were enzymatically determined using an auto-analyzer (Hitachi Model 7170 analyzer; Hitachi, Ltd., Tokyo, Japan). The weight and height were measured in kilograms and centimeters, respectively. Furthermore, the body mass index (BMI) was calculated as the weight divided by the height squared.

For DTC patients, after I-131 therapy, thyroxine replacement therapy was initiated. Levothyroxine sodium tablets (Euthyrox; Merck KGaA, Darmstadt, Germany) was administered to all DTC patients, with an individualized dose administered to anyone for maintaining a suppressed TSH level. One month later, re-assessments on the thyroid hormone levels and serum lipid levels were performed. For this purpose, 157 DTC patients (36 males and 121 females) had adequate information for analysis.

The present study was ethically approved by the Institutional Review Board of Tianjin Medical University General Hospital, and the clinical investigation was conducted according to the principles expressed in the Declaration of Helsinki. In addition, informed consent was obtained from each of the participants.

Diagnostic criteria and grouping. The diagnostic criteria for dyslipidemia were in accordance with the National Cholesterol Education Program Adult Treatment Panel III criteria as follows: $\mathrm{TC} \geq 5.18 \mathrm{mmol} / 1, \mathrm{TG} \geq 1.70 \mathrm{mmol} / 1$, LDL-C $\geq 3.37 \mathrm{mmol} / 1$ and HDL-C $<1.04 \mathrm{mmol} / 1$ (13). All of the subjects were divided into subgroups according to the serum TSH levels, namely: Subgroup 1, subjects with a normal TSH level $(<5 \mu \mathrm{IU} / \mathrm{ml})$; subgroup 2 , subjects with a TSH level between 5 and $30 \mu \mathrm{IU} / \mathrm{ml}$; and subgroup 3, subjects with a TSH level $>30 \mu \mathrm{IU} / \mathrm{ml}$. Age groups included: Age group 1, <30 years; group 2, 30-39 years; group 3, 40-49 years; group 4, 50-59 years; and group 5, $\geq 60$ years.

Statistical analysis. Data were presented as mean \pm standard deviation. Statistical analysis was performed with SPSS 19.0 (IBM SPSS, Armonk, NY, USA), and the independent sample t-test was used to compare parameter concentrations between the DTC and control group, as well as prior to and following treatment with thyroxine. Pearson bivariate correlations were calculated for TC, TG, LDL-C and HDL-C with $\mathrm{FT}_{3}, \mathrm{FT}_{4}$ and TSH in different genders, respectively. Furthermore, the odds ratio (OR) for hyperlipidemia with $95 \%$ confidence intervals was calculated by binary logistic regression models. $\mathrm{P}<0.05$ was used to indicate a statistically significant difference.

\section{Results}

Patient characteristics. The values of various parameters for subjects in the DTC and control groups prior to I-131 therapy are reported in Table I. There was no difference in age between the two groups. Furthermore, the subjects in the DTC group demonstrated significantly higher TSH levels and lower thyroid hormone levels compared with those in the control group. BMI, as well as serum TC, TG and LDL-C levels, were also significantly higher in the DTC group than in the control group.

Serum lipid profiles. The serum lipid profiles for patients according to gender and age group are presented (Figs. 1-4). In males, the levels of TC and LDL-C in the two groups, as well as the TG levels in the DTC group, reached the highest level for individuals between the ages of 40 and 50 years, then gradually decreased with age. By contrast, TG levels in the control group were highest between the ages of 30 and 40 years, decreased over the next two decades, and then increased with age. In females, the TC and LDL-C levels increased gradually with age in both groups, while the TG level tended to increase with age until the 50-60-year age range in the DTC group.

Dyslipidemia. Dyslipidemia prevalence was investigated in different TSH subgroups in both genders (Fig. 5). Prevalences of hypercholesteremia and high LDL-C in females were slightly higher compared with those in males (TC, 65.02 vs. $64.05 \%$; LDL-C, 50.95 vs. $48.32 \%$ ). As the serum TSH level increased, the prevalences of hypercholesteremia and high LDL-C increased. In subgroup 1, the prevalences of hypercholesteremia and high LDL-C in males (43.33 and $26.67 \%$, respectively) were slightly higher than those in females (41.73 and $25.59 \%$, respectively). Furthermore, the prevalences of hypercholesteremia and high LDL-C in females increased more than those of males as the TSH level increased. By contrast, the prevalences of hypertriglyceridemia and low HDL-C were significantly higher in males compared with females (TG, 55.06 vs. 34.79\%; HDL-C, 18.54 vs. 3.80\%). The incidence of hypertriglyceridemia rose as the serum TSH level increased, however, the incidence of HDL-C was reduced.

Changes in parameters after thyroxine treatment. Parameters prior to and 1 month following thyroxine treatment are shown in Table II. Significant changes could be observed in thyroid hormones and serum lipid concentrations in all DTC patients. Following treatment, the mean levels of serum TC, TG and LDL-C decreased by $1.77,0.62$ and $1.31 \mathrm{mmol} / 1$ respectively. Furthermore, the difference in HDL-C levels between prior to and following treatment was not significant. 
Table I. Parameters of patients in the DTC and control groups prior to I-131 therapy.

\begin{tabular}{lcc}
\hline Parameters & DTC group $(\mathrm{n}=352)$ & Control group (n=352) \\
\hline Male & 89 & 89 \\
Female & 263 & 263 \\
Age $(\mathrm{years})$ & $48.73 \pm 12.81$ & $48.75 \pm 12.78$ \\
$\mathrm{BMI}\left(\mathrm{kg} / \mathrm{m}^{2}\right)$ & $25.92 \pm 3.49^{\mathrm{a}}$ & $25.16 \pm 3.93$ \\
$\mathrm{FT}_{3}(\mathrm{pmol} / \mathrm{l})$ & $2.08 \pm 0.71^{\mathrm{a}}$ & $5.07 \pm 0.49$ \\
$\mathrm{FT}_{4}(\mathrm{pmol} / \mathrm{l})$ & $5.62 \pm 2.06^{\mathrm{a}}$ & $15.93 \pm 2.12$ \\
$\mathrm{TSH}(\mu \mathrm{IU} / \mathrm{ml})$ & $84.26 \pm 45.33^{\mathrm{a}}$ & $2.53 \pm 1.40$ \\
$\mathrm{TC}(\mathrm{mmol} / \mathrm{l})$ & $6.63 \pm 1.39^{\mathrm{a}}$ & $5.04 \pm 0.97$ \\
$\mathrm{TG}(\mathrm{mmol} / \mathrm{l})$ & $2.25 \pm 1.82^{\mathrm{a}}$ & $1.46 \pm 0.92$ \\
$\mathrm{LDL}-\mathrm{C}(\mathrm{mmol} / \mathrm{l})$ & $4.16 \pm 1.15^{\mathrm{a}}$ & $2.85 \pm 0.84$ \\
$\mathrm{HDL}-\mathrm{C}(\mathrm{mmol} / \mathrm{l})$ & $1.59 \pm 0.44$ & $1.56 \pm 0.40$ \\
$\mathrm{UA}(\mu \mathrm{IU} / \mathrm{ml})$ & $304.10 \pm 91.21$ & $289.65 \pm 87.38$ \\
FG $(\mathrm{mmol} / \mathrm{l})$ & $5.48 \pm 1.14^{\mathrm{a}}$ & $5.23 \pm 0.85$ \\
\hline
\end{tabular}

BMI, body mass index; $\mathrm{FT}_{3}$, free triiodothyronine; $\mathrm{FT}_{4}$, free thyroxine; $\mathrm{TSH}$, thyroid-stimulating hormone; TC, total cholesterol; $\mathrm{TG}$, triglycerides; LDL-C, low-density lipoprotein cholesterol; HDL-C, high-density lipoprotein cholesterol; UA, uric acid; FG, fasting glucose. ${ }^{a} \mathrm{P}<0.01$ vs. control, analyzed by independent samples t-test.

A

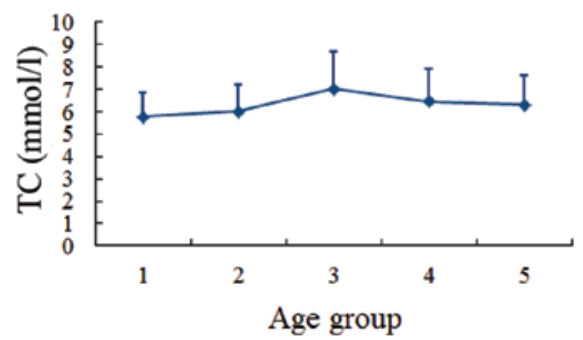

C

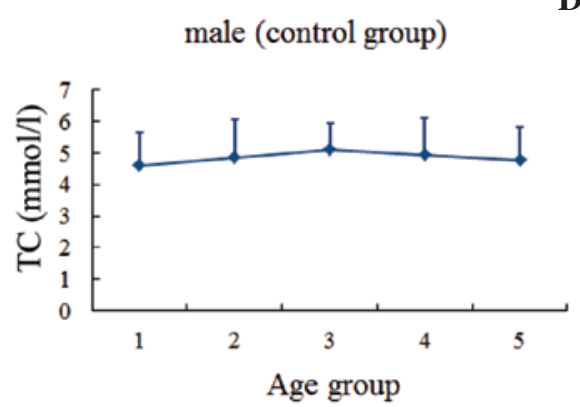

B

D female (DTC group)

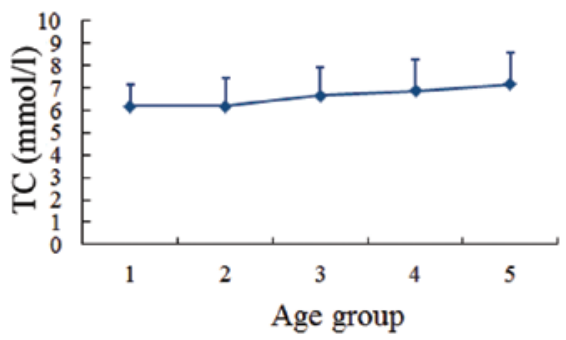

female (control group)

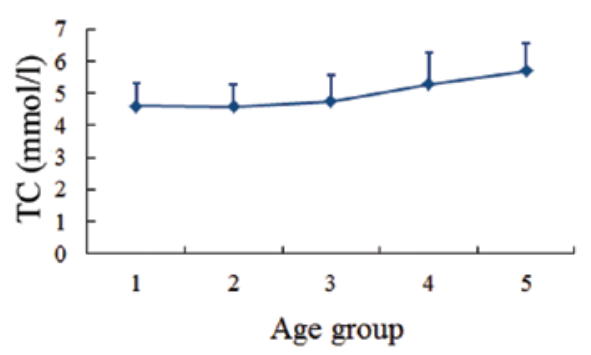

Figure 1. Serum TC level in different age groups. (A) Males and (B) females in the DTC group. (C) Males and (D) females in the control group. Age group 1, $<30$ years; group 2, 30-39 years; group 3, 40-49 years; group 4, 50-59 years; group 5, $\geq 60$ years. TC, total cholesterol; DTC, differentiated thyroid cancer.

Correlation analysis. Pearson bivariate correlation was performed in order to assess the association between thyroid hormones and lipids (Table III). This correlation analysis was performed in all the subjects, including all DTC patients and the normal controls. In both genders, a significant negative correlation was observed between free thyroid hormones and TC, TG or LDL-C levels. By contrast, there were significant positive correlations between TSH and TC, TG or LDL-C levels. In addition, a significant negative correlation between $\mathrm{FT}_{3}$ and HDL-C, and a significant positive correlation between TSH and HDL-C were identified in females, which were not observed in males.

Dyslipidemia risk analysis. Finally, the risks of developing dyslipidemia in different subgroups were investigated using binary logistic regression (Table IV). This analysis was performed in all DTC patients and the normal controls, and TSH was designated as a categorical variable. Age, BMI, UA and FG were taken as covariates. Significant differences were demonstrated when subgroup data were 
A

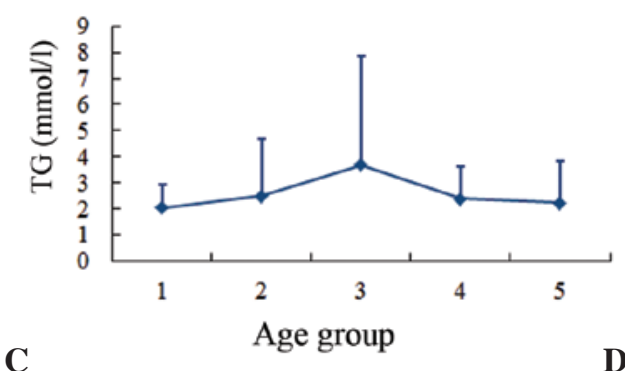

male (control group)

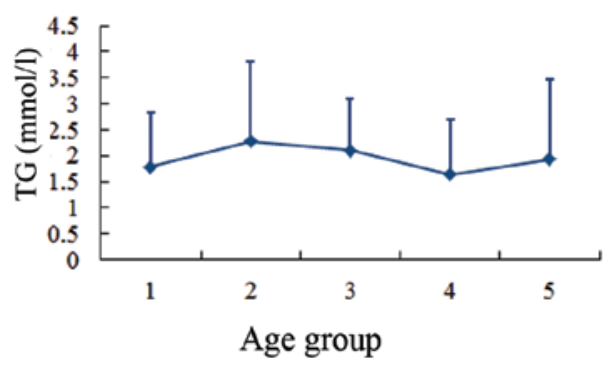

B

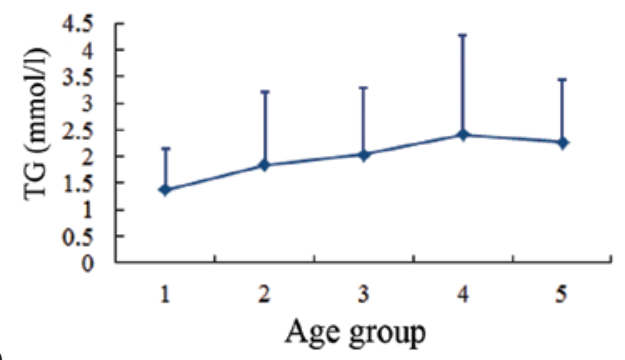

female (conrtol group)

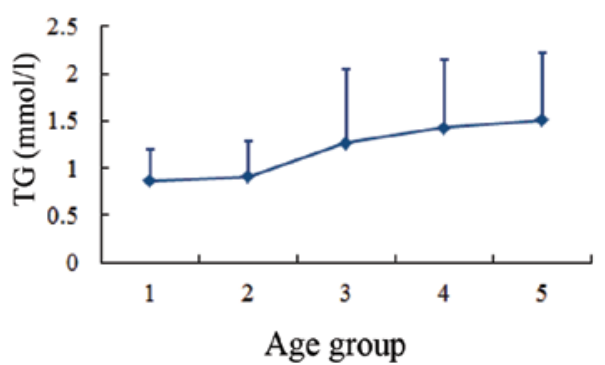

Figure 2. Serum TG level in different age groups. (A) Males and (B) females in the DTC group. (C) Males and (D) females in the control group. Age group 1, $<30$ years; group 2, 30-39 years; group 3, 40-49 years; group 4, 50-59 years; group 5, $\geq 60$ years. TG, triglycerides; DTC, differentiated thyroid cancer.

A

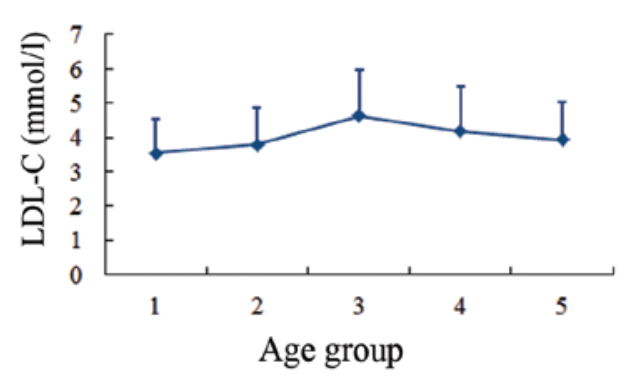

C

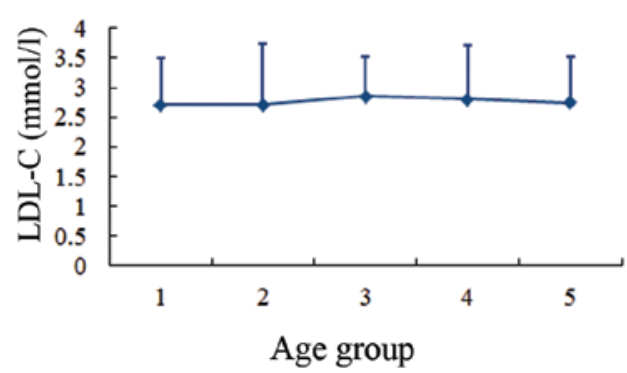

B

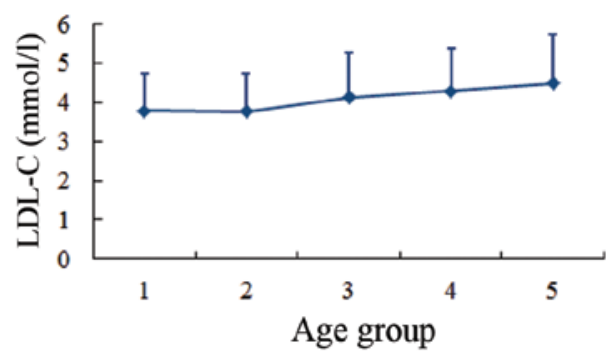

D

female (control group)

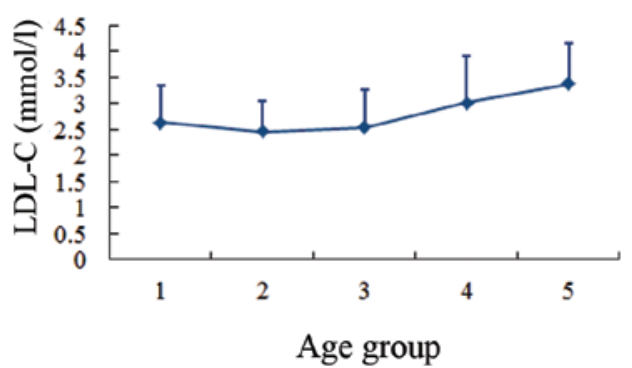

Figure 3. Serum LDL-C level in different age groups. (A) Males and (B) females in the DTC group. (C) Males and (D) females in the control group. Age group 1, <30 years; group 2, 30-39 years; group 3, 40-49 years; group 4, 50-59 years; group 5, $\geq 60$ years. LDL-C, low-density lipoprotein-cholesterol; DTC, differentiated thyroid cancer.

compared in different genders. By taking subgroup 1 as a reference, subjects of the other two subgroups had a higher risk of developing dyslipidemia. The ORs of high TC, TG and LDL-C increased progressively in both genders with the increasing TSH values. For example, the ORs of devel- oping high TC in subgroup 2 were 3.30 in males and 4.60 in females. However, in subgroup 3, the ORs were 9.40 in males and 13.12 in females. The magnitude of gender differences was also examined. Firstly, the ORs of dyslipidemia were higher in females compared with males. Secondly, for males, 
A

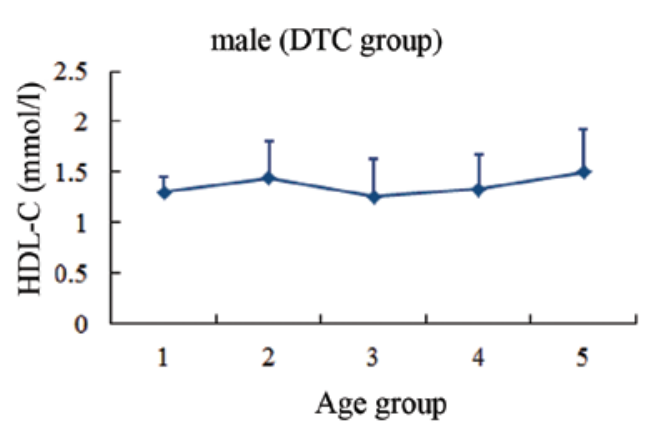

C

male (control group)

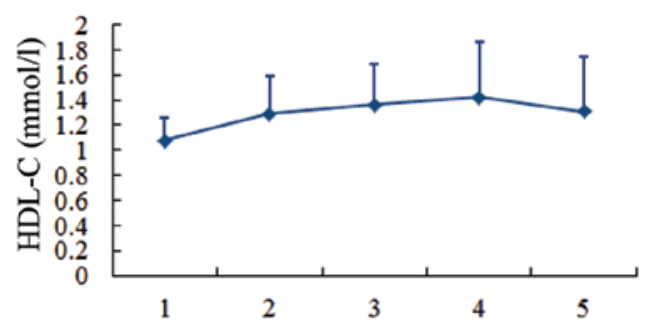

Age group
B

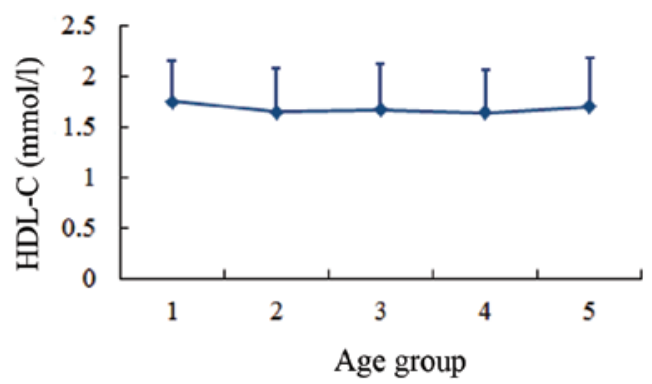

D

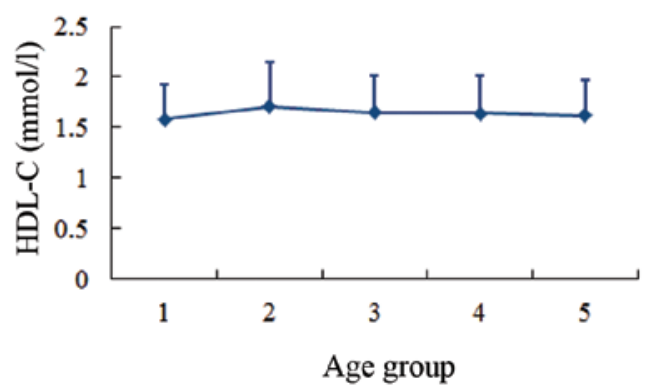

Figure 4. Serum HDL-C level in different age groups. (A) Males and (B) females in the DTC group. (C) Males and (D) females in the control group. Age group 1, <30 years; group 2, 30-39 years; group 3, 40-49 years; group 4, 50-59 years; group 5, $\geq 60$ years. HDL-C, high-density lipoprotein-cholesterol; DTC, differentiated thyroid cancer.

A

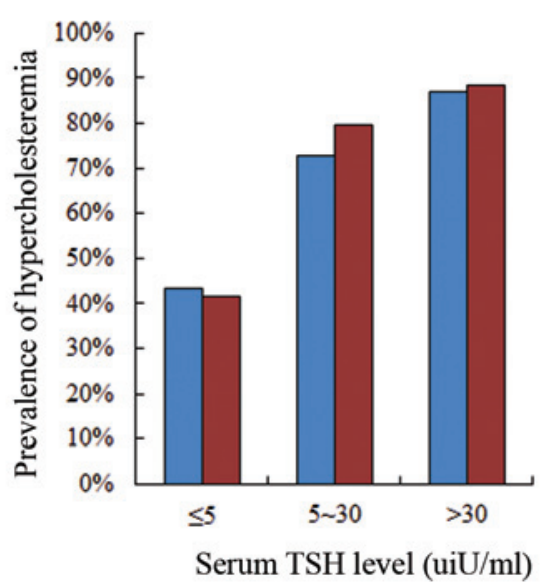

C

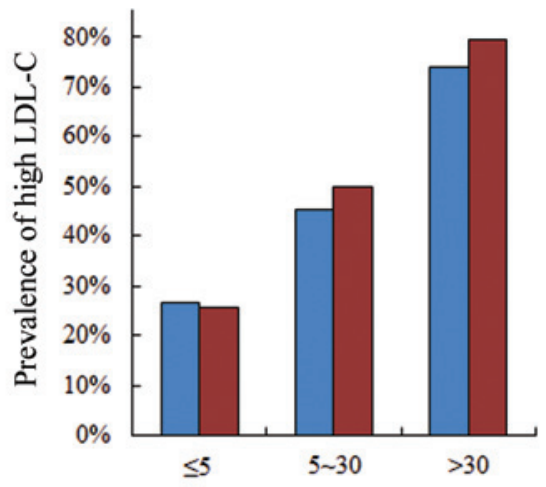

Serum TSH level (uiU/ml)
B

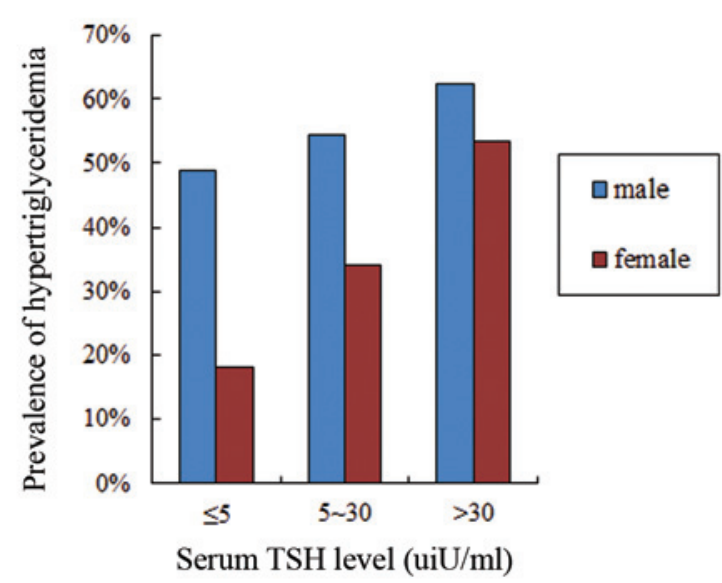

D

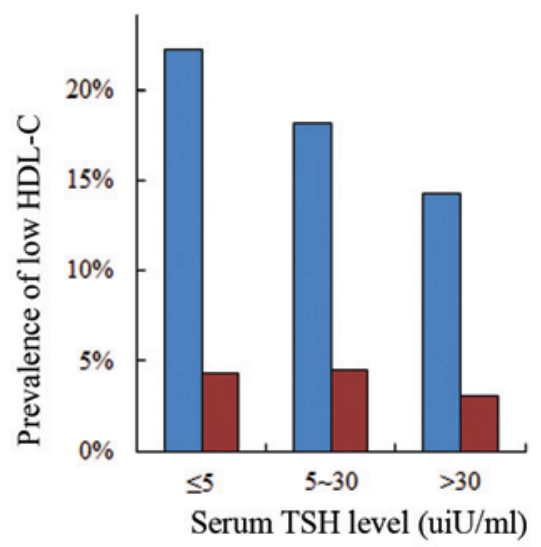

Figure 5. Frequencies of dyslipidemia prevalences according to serum thyroid stimulating hormone (TSH) level and gender. Blue bars represent males and red bars represent females. Prevalence of (A) hypercholesteremia, (B) hypertriglyceridemia, (C) low-density lipoprotein-cholesterol (LDL-C) and (D) high-density lipoprotein-cholesterol (HDL-C). 
only the ORs of developing high TC and LDL-C had a statistical significance. However for females, the OR of developing hypertriglyceridemia was also significant.

\section{Discussion}

It is well known that thyroid hormones affect lipid metabolism. However, almost all the populations studied thus far were suffering from benign thyroid diseases, including subclinical hypothyroidism, and overt hypothyroid or hyperthyroid (4). The population in the present study comprised DTC patients following partial or total thyroidectomy. These DTC patients, who were ready to receive I-131 therapy were put into a state of severe hypothyroidism from euthyroidism in a short period of time. The aim of the present study was to estimate the association between thyroid hormones and serum lipids in the population studied, and to investigate whether the risk of hyperlipidemia differed between genders.

Thyroid hormones and TSH have different effects on lipid metabolism. Thyroid hormones affect serum lipid levels by increasing the elimination of neutral sterols and bile acids (2), and by reducing the absorption of cholesterol in the intestines (14). Two animal studies have revealed that thyroid hormones can stimulate the hepatic LDL-C receptor and increase the removal of LDL-C from the circulation $(2,3)$. Boone et al (2) revealed that thyroid hormones enhanced the cholesterol-accepting capacity of serum via the ABCA1 transporter. Furthermore, Ness et al (3) demonstrated that the hypocholesterolemic effect of thyroid hormone resulted from the expression of the hepatic cholesterol $7 \alpha$ hydroxylase gene. Tan et al (15) suggested that thyroid hormones could increase the activity of hepatic lipase and thereby reduce serum TC levels. However, TSH has an opposite effect on the metabolism of lipids. In addition to thyroid cells, TSH receptors are also expressed in many extrathyroidal tissues, including the liver $(16,17)$. TSH binds to the TSH receptor on hepatocytes and stimulates the cyclic adenosine monophosphate/protein kinase A/cyclic adenosine monophosphate-responsive element binding protein signaling system. In this way, TSH upregulates the expression of 3-hydroxy-3-methyl-glutaryl coenzyme A reductase, a rate-limiting enzyme in cholesterol synthesis, which can modulate lipoprotein metabolism and facilitate cholesterol uptake by the liver $(7,16,17)$. Two cross-sectional studies discovered that TSH levels were associated with serum lipid profiles independent of thyroid hormones (7,17). Furthermore, Wang et al (7) observed that TSH levels induced a significant direct effect on TC levels. Xu et al (17) quantitatively demonstrated that each $1 \mu \mathrm{IU} / \mathrm{ml}$ increase in the TSH level tended to elevate the TC level by $0.016 \mathrm{mmol} / \mathrm{l}$.

In the current study, DTC patients who required I-131 therapy following partial or total thyroidectomy did not take thyroxine medication. During this phase, some acute changes occurred in the serum parameters, including dyslipidemia (18). The present study revealed significant negative correlations between free thyroid hormones and serum TC, TG or LDL-C levels, as well as significant positive correlations between TSH and serum TC, TG or LDL-C levels. Furthermore, the risk of developing dyslipidemia due to high TSH level was identified as gender-related. Moreover, the
ORs for dyslipidemia were significantly higher in females than in males. Therefore, the results of the present study indicate that sex hormones may be an important contributor to this phenomenon. Tognini et al (9) also found that gender substantially influenced the association between thyroid status and serum lipid levels, and their results were in agreement with those of the present study.

With regard to the mechanism of different sex hormones' effects on lipid metabolism, testosterone and estradiol have different roles, which can be summarized as described below. First, lipoprotein lipase (LPL) and hepatic lipase (HL) are the major lipolytic enzymes of the lipoprotein metabolism. These enzymes remove TG from the bloodstream and decrease the serum chylomicron levels. Androgens stimulate HL activity, however, estrogens inhibit the HL and LPL activities (19). Secondly, testosterone increases lipolysis by stimulating $\beta$-adrenergic activity (20). Thirdly, testosterone upregulates genes responsible for HDL-C catabolism, and increases the activity of both hepatic lipase and scavenger receptor BI (SR-BI). Furthermore, SR-BI increases the uptake of lipids into hepatocytes and enhances cholesterol efflux from peripheral cells $(21,22)$. Finally, estrogen is capable of increasing cholesterol and LDL-C levels, and these metabolic effects appear to be mediated by estrogen receptor $\alpha$ (23).

Clinically, low levels of testosterone and high levels of estrogen are associated with unfavorable lipid levels $(22,24)$. Haffner et al (25) demonstrated that serum testosterone was inversely correlated with TC, TG and LDL-C, yet positively correlated with HDL-C. Several meta-analyses with the topic of the changes in lipoprotein profiles resulting from exogenous testosterone administration have been conducted (26-28). For instance, Whitsel et al (26) performed such a meta-analysis by analyzing 19 studies, and demonstrated that the intramuscular administration of testosterone esters to hypogonadal males was associated with a dosage-dependent reduction of TC and LDL-C levels. By contrast, considering estrogen, Wranicz et al (29) revealed a significantly positive correlation between estradiol levels and serum TC, TG and LDL-C levels. Ott et al (30) performed a study to explore the change of serum lipid levels of transsexuals after cross-gender therapy, and significant increases of TC, TG and HDL-C were identified in male to female transsexuals. Another study demonstrated that the estradiol concentration in males had a significant negative correlation with HDL-C concentration and a significant positive correlation with the TG level (31).

In conclusion, the present study had both strengths and weaknesses. The uniqueness of the study was that it focused attention on the correlation between TSH and serum lipid profiles in terms of different genders in DTC patients. However, due to the prevalence of DTC in females being higher than that in males, the number of males in the present study was relatively small. Another potential limitation of the present study was the lack of information on lifestyle choices of the patients, such as smoking or eating habits. This may affect the accuracy of the results. However, the careful exclusion of patients receiving lipid-lowering drugs and other treatments that have the potential to influence the lipid profile improved the statistical power. Finally, since hyperlipemia is known as a risk factor for cardiovascular diseases, whether a short-term increase of serum lipids during the 
Table II. Parameters before and after 1 month of thyroxine treatment.

\begin{tabular}{lcc}
\hline Parameters & Before treatment $(\mathrm{n}=157)$ & 1 Month after treatment $(\mathrm{n}=157)$ \\
\hline Male & 36 & 36 \\
Female & 121 & 121 \\
$\mathrm{FT}_{3}(\mathrm{pmol} / \mathrm{l})$ & $2.01 \pm 0.73^{\mathrm{a}}$ & $5.19 \pm 0.92$ \\
$\mathrm{FT}_{4}(\mathrm{pmol} / \mathrm{l})$ & $5.38 \pm 2.33^{\mathrm{a}}$ & $19.44 \pm 4.30$ \\
$\mathrm{TSH}(\mathrm{uIU} / \mathrm{ml})$ & $86.65 \pm 43.50^{\mathrm{a}}$ & $7.27 \pm 14.61$ \\
$\mathrm{TC}(\mathrm{mmol} / \mathrm{l})$ & $6.96 \pm 1.29^{\mathrm{a}}$ & $5.19 \pm 1.10$ \\
$\mathrm{TG}(\mathrm{mmol} / \mathrm{l})$ & $2.25 \pm 1.40^{\mathrm{a}}$ & $1.63 \pm 1.05$ \\
$\mathrm{LDL}-\mathrm{C}(\mathrm{mmol} / \mathrm{l})$ & $4.40 \pm 1.11^{\mathrm{a}}$ & $3.09 \pm 0.98$ \\
$\mathrm{HDL}-\mathrm{C}(\mathrm{mmol} / \mathrm{l})$ & $2.69 \pm 12.80$ & $1.40 \pm 0.52$
\end{tabular}

$\mathrm{FT}_{3}$, free triiodothyronine; $\mathrm{FT}_{4}$, free thyroxine; TSH, thyroid-stimulating hormone; TC, total cholesterol; TG, triglycerides; LDL-C, low-density lipoprotein cholesterol; HDL-C, high-density lipoprotein cholesterol. ${ }^{\mathrm{a}} \mathrm{P}<0.01 \mathrm{vs}$. after treatment, analyzed by independent samples t-test.

Table III. Pearson bivariate correlations (r) between thyroid function and serum lipids.

\begin{tabular}{lccc}
\hline Gender & TC & TG & LDL-C \\
\hline Male (n=178) & & & $-0.57^{\mathrm{a}}$ \\
$\mathrm{FT}_{3}$ & $-0.55^{\mathrm{a}}$ & $-0.18^{\mathrm{a}}$ & $-0.54^{\mathrm{a}}$ \\
$\mathrm{FT}_{4}$ & $-0.51^{\mathrm{a}}$ & $-0.17^{\mathrm{a}}$ & -0.09 \\
$\mathrm{TSH}$ & $0.50^{\mathrm{a}}$ & $0.28^{\mathrm{a}}$ & -0.05 \\
Female (n=526) & & & 0.01 \\
$\mathrm{FT}_{3}$ & $-0.62^{\mathrm{a}}$ & $-0.33^{\mathrm{a}}$ & $-0.59^{\mathrm{a}}$ \\
$\mathrm{FT}_{4}$ & $-0.58^{\mathrm{a}}$ & $-0.32^{\mathrm{a}}$ & $-0.55^{\mathrm{a}}$ \\
$\mathrm{TSH}^{\mathrm{a} H}$ & $0.55^{\mathrm{a}}$ & $0.29^{\mathrm{a}}$ & $0.52^{\mathrm{a}}$ \\
\hline
\end{tabular}

$\mathrm{FT}_{3}$, free triiodothyronine; $\mathrm{FT}_{4}$, free thyroxine; $\mathrm{TSH}$, thyroid-stimulating hormone; TC, total cholesterol; TG, triglycerides; LDL-C, low-density lipoprotein cholesterol; HDL-C, high-density lipoprotein cholesterol; Significant at ${ }^{\mathrm{a}} \mathrm{P}<0.01$ or ${ }^{\mathrm{b}} \mathrm{P}<0.05$.

Table IV. Likelihood of developing dyslipidemia in different genders by the logistic regression model.

\begin{tabular}{lcccc}
\hline Gender & $\begin{array}{c}\mathrm{TC} \geq 5.18 \mathrm{mmol} / 1 \\
\text { OR }(95 \% \mathrm{CI})\end{array}$ & $\begin{array}{c}\mathrm{TG} \geq 1.7 \mathrm{mmol} / \mathrm{l} \\
\text { OR }(95 \% \mathrm{CI})\end{array}$ & $\begin{array}{c}\text { LDL-C } \geq 3.37 \mathrm{mmol} / 1 \\
\text { OR }(95 \% \mathrm{CI})\end{array}$ & $\begin{array}{c}\mathrm{HDL}-\mathrm{C}<1.04 \mathrm{mmol} / \mathrm{l} \\
\text { OR }(95 \% \mathrm{CI})\end{array}$ \\
\hline $\begin{array}{l}\text { Male (n=178) } \\
\text { TSH subgroup 2 }\end{array}$ & $3.30(0.78-13.92)$ & $1.35(0.34-5.30)$ & $2.63(0.67-10.29)$ & $0.72(0.13-3.91)$ \\
TSH subgroup 3 & $9.40^{\mathrm{a}}(4.17-21.15)$ & $1.83(0.92-3.63)$ & $9.60^{\mathrm{a}}(4.53-20.35)$ & $0.50(0.21-1.19)$ \\
Female (n=526) & & & & \\
TSH subgroup 2 & $4.60^{\mathrm{a}}(2.05-10.30)$ & $1.85(0.88-3.88)$ & $2.52^{\mathrm{a}}(1.27-4.97)$ & $1.08(0.23-5.13)$ \\
TSH subgroup 3 & $13.12^{\mathrm{a}}(7.74-22.25)$ & $5.50^{\mathrm{a}}(3.50-8.65)$ & $12.98^{\mathrm{a}}(8.11-20.78)$ & $0.68(0.25-1.83)$ \\
\hline
\end{tabular}

TSH was designated as a categorical variable; age, body mass index, uric acid and fasting glucose were taken as covariates; TSH subgroup 2 (5-30 $\mu \mathrm{IU} / \mathrm{ml})$ and TSH subgroup 3 (>30 $\mu \mathrm{IU} / \mathrm{ml})$ were compared with TSH subgroup 1 (normal level). TSH, thyroid-stimulating hormone; TC, total cholesterol; TG, triglycerides; LDL-C, low-density lipoprotein cholesterol; HDL-C, high-density lipoprotein cholesterol; OR, odds ratio; CI, confidence interval. ${ }^{\mathrm{P}}<0.01$.

thyroid hormone withdrawal period will increase the risk of cardiovascular diseases requires further investigation.

In summary, the present study systematically analyzed the association between the serum TSH profile and serum lipid levels in DTC patients, and the influence of different genders on this correlation. Furthermore, DTC patients after thyroidectomy were demonstrated to be in a severe state of hypothyroidism, which increased the risk of dyslipidemia. In addition, female patients were shown to have a higher risk of dyslipidemia compared with males. 


\section{Acknowledgements}

This study was supported by the National Key Clinical Specialty Project (awarded to the Departments of Nuclear Medicine and Radiology). This study was supported by Tianjin Medical University General Hospital New Century Excellent Talent Program; Young and Middle-aged Innovative Talent Training Program from Tianjin Education Committee; and Talent Fostering Program (the 131 Project) from Tianjin Education Committee, Tianjin Human Resources and Social Security Bureau (awarded to Zhaowei Meng). This study was also supported by China National Natural Science Foundation (grant no. 81571709) and the Key Project of Tianjin Science and Technology Committee Foundation (grant no. 16JCZDJC34300; awarded to Zhaowei Meng).

\section{References}

1. American Thyroid Association (ATA) Guidelines Taskforce on Thyroid Nodules and Differentiated Thyroid Cancer; Cooper DS, Doherty GM, Haugen BR, Kloos RT, Lee SL, Mandel SJ, Mazzaferri EL, McIver B, Pacini F, Schlumberger M, et al: Revised American Thyroid Association management guidelines for patients with thyroid nodules and differentiated thyroid cancer. Thyroid 19: 1167-1214, 2009.

2. Boone LR, Lagor WR, Moya Mde L, Niesen MI, Rothblat GH and Ness GC: Thyroid hormone enhances the ability of serum to accept cellular cholesterol via the ABCA1 transporter. Atherosclerosis 218: 77-82, 2011

3. Ness GC, Pendleton LC, Li YC and Chiang JY: Effect of thyroid hormone on hepatic cholesterol 7 alpha hydroxylase, LDL receptor, HMG-CoA reductase, farnesyl pyrophosphate synthetase and apolipoprotein A-I mRNA levels in hypophysectomized rats. Biochem Biophys Res Commun 172: 1150-1156, 1990.

4. Walsh JP, Bremner AP, Bulsara MK, O'leary P, Leedman PJ, Feddema $\mathrm{P}$ and Michelangeli V: Thyroid dysfunction and serum lipids: A community-based study. Clin Endocrinol (Oxf) 63: 670-675, 2005.

5. Bauer DC, Ettinger B and Browner WS: Thyroid functions and serum lipids in older women: A population-based study. Am J Med 104: 546-551, 1998.

6. Chubb SA, Davis WA and Davis TM: Interactions among thyroid function, insulin sensitivity and serum lipid concentrations: The Fremantle diabetes study. J Clin Endocrinol Metab 90: 5317-5320, 2005.

7. Wang F, Tan Y, Wang C, Zhang X, Zhao Y, Song X, Zhang B, Guan Q, Xu J, Zhang J, et al: Thyroid-stimulating hormone levels within the reference range are associated with serum lipid profiles independent of thyroid hormones. J Clin Endocrinol Metab 97: 2724-2731, 2012.

8. Meier C, Staub JJ, Roth CB, Guglielmetti M, Kunz M, Miserez AR, Drewe J, Huber P, Herzog R and Müller B: TSH-controlled L-thyroxine therapy reduces cholesterol levels and clinical symptoms in subclinical hypothyroidism: A double blind, placebo-controlled trial (Basel Thyroid Study). J Clin Endocrinol Metab 86: 4860-4866, 2001.

9. Tognini S, Polini A, Pasqualetti G, Ursino S, Caraccio N, Ferdeghini M and Monzani F: Age and gender substantially influence the relationship between thyroid status and the lipoprotein profile: Results from a large cross-sectional study. Thyroid 22: 1096-1103, 2012.

10. Bindels AJ, Westendorp RG, Frölich M, Seidell JC, Blokstra A and Smelt AH: The prevalence of subclinical hypothyroidism at different total plasma cholesterol levels in middle aged men and women: A need for case-finding?. Clin Endocrinol (Oxf) 50: 217-220, 1999

11. Iqbal A, Jorde R and Figenschau Y: Serum lipid levels in relation to serum thyroid-stimulating hormone and the effect of thyroxine treatment on serum lipid levels in subjects with subclinical hypothyroidism: The Troms $\varnothing$ study. J Intern Med 260: 53-61, 2006.

12. Boekholdt SM, Titan SM, Wiersinga WM, Chatterjee K, Basart DC, Luben R, Wareham NJ and Khaw KT: Initial thyroid status and cardiovascular risk factors: The EPIC-Norfolk prospective population study. Clin Endocrinol (Oxf) 72: 404-410, 2010.
13. National Cholesterol Education Program (NCEP) Expert Panel on Detection, Evaluation, and Treatment of High Blood Cholesterol in Adults (Adult Treatment Panel III): Third Report of the National Cholesterol Education Program (NCEP) Expert Panel on Detection, Evaluation and Treatment of High Blood Cholesterol in Adults (Adult Treatment Panel III) final report. Circulation 106: 3143-3421, 2002.

14. Gälman C, Bonde Y, Matasconi M, Angelin B and Rudling M: Dramatically increased intestinal absorption of cholesterol following hypophysectomy is normalized by thyroid hormone. Gastroenterology 134: 1127-1136, 2008.

15. Tan KC, Shiu SW and Kung AW: Plasma cholesteryl ester transfer protein activity in hyper- and hypothyroidism. J Clin Endocrinol Metab 83: 140-143, 1998.

16. Tian L, Song Y, Xing M, Zhang W, Ning G, Li X, Yu C, Qin C, Liu J, Tian X, et al: A novel role for thyroid-stimulating hormone: Up-regulation of hepatic 3-hydroxy-3-methyl-glutarylcoenzyme A reductase expression through the cyclic adenosine monophosphate/protein kinase A/cyclic adenosine monophosphate-responsive element binding protein pathway. Hepatology 52: 1401-1409, 2010.

17. Xu C, Yang X, Liu W, Yuan H, Yu C, Gao L and Zhao J: Thyroid stimulating hormone, independent of thyroid hormone, can elevate the serum total cholesterol level in patients with coronary heart disease: A cross-sectional design. Nutr Metab (Lond) 9: 44, 2012.

18. Regalbuto C, Alagona C, Maiorana R, Di Paola R, Cianci M, Alagona G, Sapienza S, Vigneri R and Pezzino V: Acute changes in clinical parameters and thyroid function peripheral markers following L-T4 withdrawal in patients totally thyroidectomized for thyroid cancer. J Endocrinol Invest 29: 32-40, 2006.

19. Agledahl I, Skjaerpe PA, Hansen JB and Svartberg J: Low serum testosterone in men is inversely associated with non-fasting serum triglycerides: The Troms $\varnothing$ study. Nutr Metab Cardiovasc Dis 18: 256-262, 2008

20. Haffner SM and Valdez RA: Endogenous sex hormones: Impact on lipids, lipoproteins and insulin. Am J Med 98: 40S-47S, 1995.

21. Langer C, Gansz B, Goepfert C, Engel T, Uehara Y, von Dehn G, Jansen H, Assmann $\mathrm{G}$ and von Eckardstein A: Testosterone up-regulates scavenger receptor BI and stimulates cholesterol efflux from macrophages. Biochem Biophys Res Commun 296: 1051-1057, 2002.

22. Monroe AK and Dobs AS: The effect of androgens on lipids. Curr Opin Endocrinol Diabetes Obes 20: 132-139, 2013.

23. Pellegrini M, Pallottini V, Marin R and Marino M: Role of the sex hormone estrogen in the prevention of lipid disorder. Curr Med Chem 21: 2734-2742, 2014.

24. Mäkinen JI, Perheentupa A, Irjala K, Pöllänen P, Mäkinen J, Huhtaniemi I and Raitakari OT: Endogenous testosterone and serum lipids in middle-aged men. Atherosclerosis 197: 688-693, 2008.

25. Haffner SM, Mykkänen L, Valdez RA and Katz MS: Relationship of sex hormones to lipids and lipoproteins in nondiabetic men. J Clin Endocrinol Metab 77: 1610-1615, 1993.

26. Whitsel EA, Boyko EJ, Matsumoto AM, Anawalt BD and Siscovick DS: Intramuscular testosterone esters and plasma lipids in hypogonadal men: A meta-analysis. Am J Med 111: 261-269, 2001 .

27. Calof OM, Singh AB, Lee ML, Kenny AM, Urban RJ, Tenover JL and Bhasin S: Adverse events associated with testosterone replacement in middle-aged and older men: A meta-analysis of randomized, placebo-controlled trials. J Gerontol A Biol Sci Med Sci 60: 1451-1457, 2005.

28. Isidori AM, Giannetta E, Greco EA, Gianfrilli D, Bonifacio V, Isidori A, Lenzi A and Fabbri A: Effects of testosterone on body composition, bone metabolism and serum lipid profile in middle-aged men: A meta-analysis. Clin Endocrinol (Oxf) 63: 280-293, 2005.

29. Wranicz JK, Cygankiewicz I, Rosiak M, Kula P, Kula K and Zareba W: The relationship between sex hormones and lipid profile in men with coronary artery disease. Int J Cardiol 101: 105-110, 2005.

30. Ott J, Aust S, Promberger R, Huber JC and Kaufmann U: Cross-sex hormone therapy alters the serum lipid profile: A retrospective cohort study in 169 transsexuals. J Sex Med 8: 2361-2369, 2011

31. Yasui T, Uemura H, Irahara M, Arai M, Kojimahara N, Okabe R, Ishii Y, Tashiro S and Sato H: Associations of endogenous sex hormones and sex hormone-binding globulin with lipid profiles in aged Japanese men and women. Clin Chim Acta 398: 43-47, 2008 . 